\title{
Vigilancia y control de los recursos marinos en el Distrito Norte de la Baja California, 1916-1932
}

Surveillance and Control of Marine Resources in the Northern District of Baja California, 1916-1932

César Alexis Marcial Campos

José Alfredo Gómez Estrada

\section{Resumen}

Palabras clave

Abstract

Keywords

Maestro en Historia por el Instituto de Investigaciones Históricas de la Universidad Autónoma de Baja California (IIH-UABC), campus Tijuana. Docente en Ateneo Universitario. Se publicación más reciente es Un territorio en disputa. El Distrito Norte de la Baja California durante el gobierno de Esteban Cantú, 1915-1920. México: Archivo Histórico de Baja California Sur-Pablo L. Martínez, Consejo Nacional para la Cultura y las Artes (2016).

Doctor en Ciencias Sociales con especialidad en Historia por el Centro de Investigaciones y Estudios Superiores en Antropología Social (CIESAS), Occidente. Investigador de tiempo completo y docente en el programa de Maestría y Doctorado del IIH-UABC. Su publicación más reciente es "Continuidad y cambios en las actividades turísticas de Tijuana, 1920-1949”, en Región y sociedad 30 (72), 2018.

Correos electrónicos: calexismarcialc@gmail.comy jalfge@yahoo.com

Este artículo analiza las medidas del gobierno federal para obtener recursos durante los años de 1916 a 1932, por medio de la regulación pesquera en Baja California. Se describe y explica la explotación ilegal de los recursos marinos por parte de pescadores locales y provenientes de California, así como las tareas realizadas por las organizaciones gubernamentales de pesca dependientes de la Secretaría de Agricultura y Fomento, así como los efectos que tuvieron la expedición de leyes y decretos sobre concesionarios acostumbrados a explotar los recursos marinos del litoral bajacaliforniano sin cumplir con sus obligaciones contractuales.

Baja California, pesca, regulación, vigilancia, recaudación

This article analyzes the federal government's measures to obtain resources during the years 1916 to 1932, fishing regulation in Baja California. It describes and explains the illegal exploit of marine resources by local fishermen and those from California, as well as the tasks carried out by the governmental fisheries organizations under the Secretaría de Agricultura y Fomento, as well as the impact the issuance of laws and decrees on concessionaries that used to exploit the marine resources of the Baja California without fulfilling their contractual obligations.

Lower California, fishing, regulations, surveillance, income

Recibido/Received

Aprobado/Approved
31 de enero de 2018

8 de mayo de 2018 


\section{Vigilancia y control de los recursos marinos en el Distrito Norte de la Baja California, 1916-1932}

César Alexis Marcial Campos y José Alfredo Gómez Estrada

\section{Introducción}

Una problemática que enfrentaron los gobiernos erigidos después de terminar la lucha de facciones revolucionarias en 1915 fue la reconstrucción del país. De 1916 a 1932 el ejecutivo en turno sufrió dificultades relacionadas con la falta de recursos económicos y materiales para llevar a cabo sus funciones gubernamentales de manera eficiente por lo que buscaron optimizar ingresos y reducir gastos, reorganizar la administración pública y hacer eficientes las dependencias de gobierno. ${ }^{1}$ Con estas medidas esperaban, entre otras cosas, controlar y aprovechar las riquezas naturales del territorio que antes habían permanecido fuera del alcance de la autoridad federal debido a la falta de vigilancia y a la evasión de particulares, aspectos que perjudicaron al erario. Dicha problemática, que se abordará a continuación, se puede observar al investigar la vigilancia y aplicación de controles sobre los recursos marinos en el Distrito Norte de la Baja California durante los años de 1916-1932.

El Distrito Norte, a diferencia de otros estados del país, no sufrió los estragos causados por la lucha armada que inició en 1910 y experimentó un despunte en la economía gracias a las inversiones de consorcios estadunidenses en agricultura y servicios turísticos. La vecindad con California, la falta de caminos y transportes dentro del Distrito Norte y la relativa incomunicación con el resto

${ }^{1}$ Zebadúa $(1994,255)$, Aboites $(2003,70,102)$ y Uhthoff $(2009,83)$. 
del país, así como su escasa población fueron factores que permitieron la expansión de negocios y empresas estadunidenses en la localidad y la formación de vínculos en las actividades productivas fronterizas como fue el caso de la pesca.

En el decenio de 1910 el estado de California experimentó un notable desarrollo en las actividades productivas, incluida la pesca y la industria basada en alimentos de origen marino. A lo largo de las primeras décadas del siglo xx las plantas empacadoras de pescado y mariscos californianas se multiplicaron y tuvieron un crecimiento acelerado en su producción. Las compañías pesqueras, ávidas de materia prima, extendieron sus capturas más allá de la línea divisoria internacional y comenzaron a explotar en gran escala los recursos marinos del litoral occidental de la península bajacaliforniana. Los pescadores entraban al Pacífico mexicano sin ninguna limitación, lanzaban sus redes o instalaban trampas, y luego trasladaban a su país los productos marinos obtenidos sin pagar por permisos o derechos de ningún tipo. La capacidad que los gobiernos federal y local podían ejercer sobre esta riqueza marina era casi nula por la desorganización administrativa y la escasez de fondos financieros que se reflejaban en una vigilancia marítima prácticamente inexistente.

Estas y otras actividades relacionadas con la pesca en la región ha sido un tema descuidado por la historiografía bajacaliforniana que desde la historia empresarial se ha enfocado en la agricultura y de servicios turísticos que representaron fuentes de ingresos para el gobierno federal en los decenios de 1910 y 1920. ${ }^{2}$ En términos historiográficos el presente trabajo, sigue la línea de los estudios realizados por Martha B. Loyo, Enrique Plasencia y Luz María Uhthoff sobre el proceso de reorganización federal en sus diversas secretarías y dependencias tras la destrucción del Estado porfirista en 1914 y la consiguiente necesidad del poder ejecutivo, a partir de 1917, de recuperar sus funciones, reorganizar las instituciones e imponer su autoridad en asuntos fiscales, militares y, en este caso, de fomento y control de actividades productivas. ${ }^{3}$

En este artículo nos ocupamos de las medidas y estrategias implementadas por el gobierno federal para regular la actividad pesquera en Baja California a

\footnotetext{
${ }^{2}$ Henderson (1964), Kerig (2001), Schantz (2011), Chenillo (2011).

${ }^{3}$ Loyo (2004), Uhthoff (2009) y Plasencia (2010).
} 
través de la expedición de leyes y decretos, tareas de vigilancia y control por parte de las dependencias de la Secretaría de Agricultura y Fomento en la región durante los años de 1916 a 1932. El trabajo tiene como objetivo describir y explicar las medidas que tomaron los gobiernos en turno para limitar la explotación pesquera ilegal y aprovechar el auge de la industria alimentaria californiana para incrementar sus ingresos. Las preguntas que pretendemos responder son ¿Cómo se llevó a cabo la vigilancia de los recursos marinos en Baja California por parte de los gobiernos durante este periodo? ¿Qué medidas tomaron para mejorar los controles sobre la actividad pesquera e incrementar la recaudación? ¿Mediante qué mecanismos el gobierno federal intentó prevenir la defraudación del fisco? y ¿Qué dependencias intervinieron en dicha tarea?

El trabajo está organizado en cuatro apartados, en el primero documentamos el inicio del auge de la pesca y su industria en California entre finales del siglo XIx y principios del xx, así como la creciente presencia de empresas pesqueras en la región costera del Distrito Norte de la Baja California a partir del decenio de 1910. En el segundo señalamos la creación de instituciones y formulación de leyes y decretos que permitieron al gobierno federal regular la explotación de los recursos marinos en la región a través de un sistema de vigilancia, de inspección y recaudación. Más adelante, describimos la aplicación de las medidas gubernamentales para vigilar la costa, inspeccionar y registrar las cantidades de productos marinos extraídas en aguas bajacalifornianas. En el siguiente apartado describimos la resistencia de pescadores, permisionarios y concesionarios que intentaron burlar la vigilancia e inspección de las autoridades gubernamentales en el sector pesquero, así como los escasos recursos con los que contaban las autoridades gubernamentales para llevar a cabo sus funciones en este ramo. Por último, damos a conocer un caso de estudio que ejemplifica las acciones del gobierno en contra de los concesionarios rentistas.

\section{El auge de la pesca y de la industria alimentaria en California}

Entre los años de 1780 y 1880 los recursos naturales de las costas de Baja California fueron descubiertos y registrados por cazadores de ballenas, pescadores asiáticos y europeos, “mercaderes aventureros” y científicos del Este de Estados 
Unidos que llegaron al Oeste para conocer su geografía y explotar de modo incipiente su flora y fauna. La información sobre la disponibilidad de recursos en esta región y la posibilidad de aprovecharlos se divulgó con amplitud gracias a memorias y reportes de marineros, científicos así como a noticias de hombres de negocios que se difundieron por medio de periódicos, libros y boletines durante la segunda mitad del siglo xIx y la primera década del xx. ${ }^{4}$ Por cuestiones científicas y de negocios productivos así como especulativos, el territorio que comprende California y Baja California comenzó a ser poblado por colonos, mineros, rancheros, cazadores y pescadores que construyeron asentamientos temporales y permanentes. ${ }^{5}$

Los comerciantes que en el siglo XIX abastecían a estas comunidades con manufacturas que provenían de la costa Este de Estados Unidos enfrentaron problemas para transportar con rapidez los víveres perecederos. En ese contexto las conservas y los alimentos preservados adquirieron una mayor relevancia. En 1864, después de experimentar con el envasado de salmón algunos empresarios invirtieron capital en el montaje de la primera fábrica empacadora de pescado en Sacramento, California. A partir de entonces se difundió esta técnica y los hombres de negocios involucrados en la pesca la utilizaron para ampliar las opciones ya conocidas de conservación tales como el secado, salado y ahumado. ${ }^{6}$

A finales del siglo xIx y principios del xx eran varias las empacadoras que enlataban salmón, sardina, atún y abulón. Eventualmente algunas de estas especies escasearon por cuestiones naturales pero también a causa de la sobreexplotación, aun cuando todavía la producción no era masiva pues no estaba del todo tecnificada.7 Entre 1908 y 1917 la producción de alimentos marinos enlatados se incrementó en Estados Unidos gracias a las innovaciones mecánicas que buscaban optimizar y agilizar el proceso de corte, limpieza y empaque.

4 Secretaría de Fomento (1913), Gómez (1918), Glass (1922 p. 35, 36), Mosse (1936, p. 1-24), McEvoy (1986, p. 74, 75, 84) y Bentz y Schewemmer (2002, p. 149).

5 Mosse (1936, p. 1-24, 48), Pincetl (1999, p. 8), Bentz y Schwemmer (2002, p. 140-147) y Glass (1922, p. 2).

${ }^{6}$ Brown y Phillips (1986, p. 743-756); O’Bannon (1987, p. 570-574).

7 Uno (1929, p. 1-3), O’Bannon (1982, p. 151-152), Newell (1988, p. 627), Davis (1993, p. 10-20) y Núñez (2016, p. 84). 
En el mismo periodo creció el consumo gracias a la promoción realizada por algunos empresarios interesados en introducir el pescado enlatado en la dieta de los estadunidenses. Para 1913 sobresalían en California tres pioneros en el ramo: A. P. Halfhill, F. E. Booth y Gilbert Van Camp y había nueve empacadoras que sin ser grandes produjeron ese año 115 ooo cajas de latas de atún. ${ }^{8}$

En 1914, los empresarios californianos del ramo reconocieron que el futuro de su industria dependía más de la disponibilidad de materia prima que de las limitaciones del mercado el cual crecía con rapidez. ${ }^{9} \mathrm{~A}$ fines de ese año varios pescadores se dirigieron al cónsul mexicano de la facción constitucionalista en San Diego con objeto de solicitar información sobre permisos de pesca en el Distrito Norte de la Baja California. ${ }^{10}$

Debido a la competencia por los recursos marinos en el litoral californiano, las regulaciones de pesca del gobierno estadunidense, el decrecimiento de algunas especies y la necesidad de abastecer a las factorías, los pescadores de California se vieron forzados a realizar capturas en las costas del Distrito Norte. ${ }^{11}$ Las pesquerías en Baja California aumentaron y se intensificaron gradualmente. Según R. A. Coleman, agente del Buró Estadunidense de Pesquerías, los pescadores californianos hacían capturas en el Pacífico mexicano sin respetar la línea divisoria internacional con la justificación de que en el mar las condiciones eran idénticas y no había ninguna barrera natural que sirviera de referencia para distinguir las aguas de Estados Unidos de las de México. ${ }^{12}$

En los años entre 1909 y 1916 los californianos explotaron los recursos marinos en aguas mexicanas de tres maneras: primera, de modo furtivo. Los barcos extranjeros se internaban en las aguas del Distrito Norte a pescar con relativa facilidad y libertad pues no había regulación del gobierno mexicano,

${ }^{8}$ McEvoy (1983, p. 494-521; 1986, p. 130, 131), 0`Bannon (1987, p. 570-574), Martin (1990, 8-16), Felando (1979, p. 17-24), Davis (1993, p. 10-35), Uno (1929, p. 24-56).

9 Felando (1979, p.25).

${ }^{10}$ Archivo Histórico Genaro Estrada de la Secretaría de Relaciones Exteriores (en adelante AHGE) oficio del cónsul mexicano en San Diego, California, al oficial mayor del despacho de Relaciones Exteriores, San Diego, 31 de diciembre de 1914, exp.16-14-2 bis.

${ }_{11}$ Uno (1929, p. 24-56), Felando (1979, p. 17-24), McEvoy (1983, p. 494-521), O’Bannon (1987, p. 570-574), Martin (1990, p. 8-16) y Davis (1993, p. 10-35).

12 Coleman (1922, p. 1-2). 
sistema de vigilancia ni una industria pesquera local; segunda, con permisos de la compañía La Pescadora, concesionaria y usufructuaria de los recursos marinos de toda la península y del litoral del océano Pacífico hasta Nayarit y tercera, a partir de 1916 con permisos de la Secretaría de Agricultura y Fomento, otorgados por el consulado de México en San Diego en poder de los constitucionalistas, aunque el gobierno de Venustiano Carranza, aún en lucha con las otras facciones revolucionarias, no tenía dominio sobre el territorio ni había definido los criterios para el cobro de los derechos de pesca. ${ }^{13}$

En 1916 había en California 101 plantas pescadoras; 71 se dedicaron a la distribución de productos marinos y 30 al empaque. Ese año la Comisión de Pesca de California registró 2137 botes de diverso calado y 3820 pescadores, muchos de los cuales se internaban en las aguas de Baja California. ${ }^{14}$ De acuerdo con datos del Buró de Comercio Interior y Exterior de Estados Unidos durante el año de 1918, las especies más buscadas eran bonito, barracuda y langosta, y el promedio mensual de pescado fresco capturado por pescadores de California en aguas mexicanas era de 317.5 toneladas y, según estimaciones del Buró Estadunidense de Pesquerías, las capturas anuales de langosta eran de 1814 toneladas. ${ }^{15}$

Debido a la escasez de ganado y carne en el mercado a causa de la Primera Guerra Mundial, aumentó la demanda de alimentos de origen marino de distintas especies. ${ }^{16}$ Después, a lo largo del decenio 1920 se mantuvo el consumo y producción de estos alimentos, aunque con altibajos (ver cuadro 1). Naturalmente continuaron las actividades pesqueras en la Baja California en gran medida, de acuerdo con Coleman, por el crecimiento de la población californiana, el aumento del número de pescadores y la creciente escasez de pescado

${ }^{13}$ Oficio del cónsul mexicano en San Diego, California, al oficial mayor del despacho de Relaciones Exteriores, San Diego, 31 de diciembre de 1914, AHGE, exp.16-2 bis; Memorando del jefe de la oficina de pesca marítima, México, 28 de marzo de 1936, Archivo Histórico del Gobierno del Estado de Baja California (en adelante AHGEBC), caja 413, exp. 852/671.42/998.

${ }^{14}$ Fish and Game (1917, p. 129). Las embarcaciones que refiere el boletín para ese año son 59 botes de transporte con un peso menor a las quince toneladas; 1917 botes pesqueros por debajo de las cinco toneladas; 146 , mayores de cinco y menores de quince; quince embarcaciones pesqueras mayores de $15 \mathrm{y}$ menores de 50 toneladas.

${ }^{15}$ Coleman (1922, p. 3, 4).

${ }^{16}$ Estes (1977, p. 18-23). 
en sus costas. Esto provocó que los marineros se desplazaran cada vez más a las aguas mexicanas del Distrito Norte donde abundaban muchas especies. Según los registros de la Fish and Game Commission, durante el periodo de 1916-1931 se extrajeron 40 tipos de peces entre los cuales destacaron, por su cantidad de extracción la barraduca, el bonito, fletán, lubina, listado, atún (aleta amarilla y azul). ${ }^{17}$

Este auge de la pesca y de la industria alimentaria en California tuvo repercusión en el Distrito Norte de la Baja California. En el periodo 1912-1932 se establecieron allí varias plantas empacadoras que orientaron, en su mayoría, su producción a la exportación a Estados Unidos, Japón y China como fueron las empresas de La Pescadora, la Compañía Comercial y Agrícola Mexicana, la Compañía Nacional de Productos Marinos, La Industrial de Ensenada y la Compañía Mexicana de Desarrollo Industrial, empresas impulsadas por Aurelio Sandoval, los hermanos Carlos, Guillermo y Fernando Bernstein, Abelardo L. Rodríguez, Luis M. Salazar y el japonés Masahuru Kondo. Con menor permanencia operaron La Marítima Compañía Empacadora S. A., y la Southern Reduction Company que en sus pocos años de funcionamiento se dedicaron principalmente a elaborar productos derivados de pescado tales como aceite y fertilizantes. ${ }^{18}$ La presencia de estas compañías y sus respectivas embarcaciones hizo necesaria la intervención del gobierno federal para vigilar que los recursos no fueran explotados de manera ilegal y que los permisionarios y concesionarios respetaran y cumplieron con lo estipulado en los contratos firmados con la autoridad federal.

\section{El gobierno federal y la pesca en el Distrito Norte de la Baja California}

Venustiano Carranza comenzó a intervenir en la pesca mediante una circular de la Secretaría de Agricultura y Fomento, fechada el 21 de junio de 1916. El subsecretario Pastor Rouaix declaró que quienes desearan hacer pesca comercial estarían

${ }^{17}$ Coleman (1922, p. 2); Bell y Mackenzie (1923, p. 318); California Fish and Game Commission, v. 1-18.

${ }^{18}$ Bell y Mackenzie (1923, p. 318-322), Gómez (2010, p. 164-174), Gómez (2011, p. 117-135) y Samaniego (1998, p. 553-557). 
Cuadro 1

Reporte de la California Fish and Game Commission sobre capturas de especies marinas realizadas en Baja California y enviadas a los puertos de San Diego y San Pedro, California, 1917-1931

\begin{tabular}{cc}
\hline Año & Toneladas \\
\hline 1916 & 1323.37 \\
\hline $1917^{\star}$ & 702.83 \\
\hline 1918 & 1584.92 \\
\hline 1919 & 2689.36 \\
\hline 1920 & 3166.45 \\
\hline $1921^{*}$ & 2609.24 \\
\hline $1922^{*}$ & 4426.17 \\
\hline $1923^{*}$ & 399.78 \\
\hline 1924 & 5297.07 \\
\hline 1925 & 9673.89 \\
\hline 1926 & 10096.60 \\
\hline 1927 & 24058.96 \\
\hline 1928 & 22246.36 \\
\hline $1929 *$ & 17920.88 \\
\hline 1930 & 39854.64 \\
\hline 1931 & 20013.49 \\
\hline
\end{tabular}

Fuente: Elaboración propia con base en California Fish and Game Commission, volúmenes 1-18. * Faltan los reportes trimestrales de julio-septiembre para los años de 1917, 1921 y 1929. Para 1922 faltan los reportes de la primera mitad del año y para 1923 faltan los reportes de la segunda mitad del año.

obligados a obtener permisos de esta secretaría. El día 30 de ese mismo mes, la dependencia fijó las tarifas que cobraría por explotación de productos capturados en aguas de jurisdicción federal. ${ }^{19}$ Pero durante el régimen de Carranza el nuevo Estado revolucionario no contaba todavía con ley ni reglamentos para regular las actividades pesqueras..$^{20}$ En la Constitución Política de 1917 quedó

${ }^{19}$ López (1997, p. 18).

${ }^{20}$ Agricultura y Fomento (1919, p. 93). 
asentado que la nación era propietaria de tierras y aguas, incluidos los mares territoriales, y que en todo tiempo tenía el derecho de regular el aprovechamiento de los recursos naturales, pero hasta 1924 el gobierno federal careció de ordenamientos que le permitieran reglamentar las pesquerías.

La legislación promulagada en el decenio 1920 con relación a la explotación pesquera tuvo como antecedentes la Ley de Bienes Inmuebles de la Nación y la Ley del Mar Territorial, ambas de 1902. Desde entonces se estableció que el uso de los recursos naturales existentes en las costas e islas, así como su control dentro del mar territorial (tres millas náuticas) dependían del gobierno federal. Por lo tanto, cualquier individuo, sociedad o corporación que tuviera pretensiones de explotar los recursos marinos debería someterse a las leyes y reglamentos expedidos por la federación. ${ }^{21}$

$\mathrm{Al}$ terminar la lucha de facciones revolucionarias el incipiente gobierno constitucionalista mostró especial interés en la pesca que tenía lugar en el Distrito Norte de la Baja California. A principios de 1917, la Secretaría de Agricultura y Fomento envió al Distrito Norte a Roberto Arroyo Carrillo, inspector de Caza y Pesca, con la misión de hacer un recorrido y recabar información. El inspector debió consignar que un buen número de pescadores de California explotaba el litoral occidental de la península al margen de cualquier regulación y sin beneficio alguno para el país. ${ }^{22}$

Enterado del auge de empacadoras en California y de las constantes capturas realizadas por barcos estadunidenses, el presidente Carranza tomó medidas para comenzar a cobrar derechos a los pescadores extranjeros. Con ese fin autorizó al consulado de México en San Diego para expedir permisos y cobrar impuestos, ${ }^{23}$ además dispuso la creación de oficinas para asuntos pesqueros en San Diego y San Pedro, puertos californianos donde zarpaban los barcos que se dirigían al Distrito Norte y a donde regresaban con sus respectivos cargamentos.

${ }^{21}$ López (1997, p. 17-28), Soberanes (1994, p. 2-25) y Székely (1978, p. 44, 45).

22 Acervo Documental del Instituto de Investigaciones Históricas de la Universidad Autónoma de Baja California (en adelante ADIIH-UABC) Memorándum acerca de las condiciones en que se encuentra la pesca en las aguas de la Baja California, 1925, colección Archivo General de la Nación (en adelante AGN), fondo Obregón-Calles, 8.35.

23 Sierra y Sierra (1978, p. 55). 
Estas oficinas, denominadas Servicio de Pesca, fueron establecidas en abril y junio de $1917 .{ }^{24}$

Por otra parte, el gobierno de Carranza buscaba propiciar el surgimiento de una industria nacional de productos marinos para lo cual se propuso en primera instancia poner atención a las concesiones de pesca que habían sido otorgadas. Según el presidente, este sector productivo estaba estancado y era raquítico porque por largos años había estado en manos de concesionarios especuladores y monopolizadores..$^{25}$ Consideró necesario acabar con los monopolios creados durante el gobierno porfirista y otorgar permisos a todos los pescadores e industriales interesados, así como incrementar el número de concesiones. ${ }^{26}$

Con base en la circular de junio de 1916, antes mencionada, la Secretaría de Agricultura y Fomento expidió varios permisos de pesca. El otorgado a Eduardo Suzawa, representante legal del empresario japonés Masahuru Kondo, refiere de modo implícito las disposiciones contra los monopolios. Si bien Kondo adquirió el derecho de explotar por un año toda clase de peces y concha de abulón en la costa occidental de Baja California, su contrato especificó que no tenía exclusividad ni preferencia pues la secretaría podía conceder permisos similares a cualquier persona o empresa para operar incluso dentro de la misma zona. ${ }^{27}$

Las medidas legales y administrativas de Carranza tuvieron continuidad en los gobiernos de los presidentes posteriores. Álvaro Obregón (1920-1924) promovió la creación del Reglamento de Pesca Marítima y Fluvial a través de la Secretaría de Agricultura y Fomento y del Congreso de la Unión, en 1923. Este reglamento vigente desde los primeros meses de 1924 definió las modalidades de pesca -doméstica, deportiva, comercial e industrial-, las características de las concesiones y permisos, el cobro de cuotas y tarifas, la fijación de periodos de veda y zonas de reserva, los métodos de captura autorizados y la

\footnotetext{
24 Arámburo (1942, p. 91).

25 Sierra y Sierra (1978, p. 54).

26 Hernández (1988, p. 10).

27 Copia certificada del permiso concedido por la Secretaría de Fomento, Colonización e Industria al señor Eduardo T. Suzawa el 30 de junio de 1916, AHGE, exp. 16-19-88.
} 
organización de los servicios de inspección y vigilancia. ${ }^{28}$ Poco después, durante la administración de Plutarco Elías Calles (1924-1928), el gobierno federal expidió la Ley de Pesca que entró en vigor el 7 de enero de 1925. Ambos ordenamientos fueron la base para regular las actividades de los individuos que tenían interés en aprovechar la pesca en el país, a saber: pescadores domésticos, concesionarios y permisionarios.

Tanto las leyes como reglamentos referían que la Secretaría de Agricultura y Fomento estaba encargada de regular toda explotación de productos marinos a través de sus dependencias, sin embargo, durante la presidencia de Pascual Ortiz Rubio, en 1932, otra ley separó las actividades de vigilancia e inspección de las de recaudación. Esta nueva ley estableció que la Secretaría de Hacienda se haría cargo de fijar y cobrar derechos, cuotas, tarifas y demás compensaciones fiscales así como de las disposiciones relativas a su recaudación; la Secretaría de Agricultura y Fomento solo se haría cargo de las tareas de vigilancia e inspección. ${ }^{29}$

Los gobiernos de los presidentes sonorenses buscaron poner orden en las actividades de extracción en las costas de Baja California y un funcionamiento eficiente de las oficinas involucradas para aprovechar el auge pesquero en California pues la gran mayoría de permisionarios eran californianos que hacían pesca a gran escala para vender a las empacadoras, o bien eran empresas que pescaban en embarcaciones propias para abastecer a sus plantas industriales. En 1923 el presidente Obregón creó la Dirección de Pesquerías de la cual dependían todas las agencias y oficinas de inspección. ${ }^{30}$

Las condiciones en las que estos permisionarios podían pescar en aguas nacionales quedaron asentadas en el capítulo cuarto del Reglamento y en el

${ }^{28}$ Sierra y Sierra Zepeda (1978, p. 61).

29 Reglamento de Pesca Marítima y Fluvial de la República Mexicana, emitida por la Secretaría de Agricultura y Fomento, publicada en el Diario Oficial de la Federación el 5 de enero de 1924, t. XXVI, n. 4; y 7 de enero de 1924, t. XXVI, n. 5; Ley de Pesca, publicada en el Diario Oficial de la Federación el 4 de febrero de 1925, t. XxIX, n. 29; Reglamento de Pesca Marítima y Fluvial de la República Mexicana de 1926, publicada en el Diario Oficial de la Federación el 5 de marzo de 1926, t. xxxv, n. 5; Ley de Pesca de 1932, publicada el 5 de septiembre de 1932, t. LxxIV n. 3 . 30 López (1997, p. 23). 
tercero de la Ley de Pesca. De acuerdo con los lineamientos podían explotar por un año determinadas especies, pero debían pagar expedición de permisos, cuotas de vigilancia y derechos de explotación y de exportación, según las tarifas de la secretaría así como acatar las disposiciones relativas a vedas, inspecciones y vigilancia. El gobierno esperaba obtener ingresos significativos de los permisionarios por medio de las Oficinas de Servicios de Pesca y los consulados de San Diego y Los Ángeles, California. No disponemos de información para saber cuántos permisionarios hubo a lo largo del decenio, aunque un dato aportado por un funcionario en 1925 puede darnos una idea: ese año se expidieron mensualmente un poco más de 3000 permisos para pescar en las costas de Baja California. ${ }^{31}$

A diferencia de los permisionarios, los concesionarios - un grupo reducido de mexicanos- gozaron de cinco a quince años para explotar una variedad de especies o para cultivarlas en una zona reservada y disfrutaron de incentivos tales como importar libre de impuestos embarcaciones, maquinaria y materiales para pescar así como para montar plantas y manufacturar productos. Los concesionarios también tenían derecho a ocupar terrenos nacionales y disponer de los materiales existentes en ellos para erigir fábricas y almacenes. El gobierno no obtenía de ellos ingresos significativos pues solo pagaban por la expedición de la concesión, cuotas anuales o mensuales por explotación y una fianza inicial que debía garantizar el cumplimiento de las cláusulas del contrato. No obstante, se esperaba que impulsaran el desarrollo industrial pesquero y colaboraran con el gobierno en la vigilancia de las costas para disminuir la pesca no reglamentada y el contrabando. Las obligaciones contraídas por los concesionarios eran varias, sin duda las más difíciles de cumplir tenían que ver con la inversión de capitales, la creación y funcionamiento de fábricas empacadoras y la apertura de mercados dentro del país.

\section{Medidas gubernamentales}

El cumplimiento de las expectativas gubernamentales relacionadas con la pesca requería el buen funcionamiento de las dependencias encargadas de vigilar,

${ }^{31}$ Memorándum acerca de las condiciones en que se encuentra la pesca en las aguas de la Baja California, 1925, ADIIH-UABC, AGN, fondo Obregón-Calles, 8.35. 
inspeccionar y recaudar. Los presidentes Obregón y Elías Calles mantuvieron activas las Oficinas de Servicios de Pesca en San Diego y San Pedro creadas por Carranza en 1917 y también utilizaron los consulados en Los Ángeles y San Diego, la aduana marítima de Ensenada y la agencia de Pesca en Tijuana, esta última con funciones de inspección. En 1932 el gobierno de Pascual Ortiz Rubio creó en San Diego y San Pedro las Oficinas Fiscales de Pesca, dependencia de la Secretaría de Hacienda que se haría cargo de la recaudación. ${ }^{32}$

La vigilancia de las costas del Distrito Norte era prácticamente inexistente. A finales de 1918, la Secretaría de Agricultura y Fomento informó que estaba a punto de poner en servicio un guardacostas cuyas tareas serían reforzadas después por otras embarcaciones. ${ }^{33}$ El barco en cuestión resultó ser un yate de 60 toneladas llamado Tecate que adquirió el gobierno del Distrito Norte en mayo de 1917 y cedió a la secretaría al comenzar 1919. ${ }^{34}$ El Tecate vigiló de modo precario la zona marítima desde Ensenada hasta Isla Guadalupe. A finales de 1921 el gobierno del presidente Obregón anunció por medio de la prensa que enviaría siete aeroplanos a Culiacán, Sinaloa, para realizar desde allí vuelos constantes en el Pacífico norte con el fin de detectar pescadores clandestinos y contrabandistas. ${ }^{35}$ Estos vuelos complementarían de algún modo la vigilancia del Tecate. En la segunda mitad de 1922, el presidente informó que extendería

${ }^{32}$ Reglamento de Pesca Marítima y Fluvial de la República Mexicana, emitida por la Secretaría de Agricultura y Fomento, publicada en el Diario Oficial de la Federación el 5 de enero de 1924, t. XXVI, n. 4; y 7 de enero de 1924, t. XXVI, n. 5; Ley de Pesca, publicada en el Diario Oficial de la Federación el 4 de febrero de 1925, t. xxIX, n. 29; Reglamento de Pesca Marítima y Fluvial de la República Mexicana de 1926, publicada en el Diario Oficial de la Federación el 5 de marzo de 1926, t. xxxv, n. 5; Ley de Pesca de 1932, publicada el 5 de septiembre de 1932, t. LxxIV, n. 3; Diario Oficial, de la Federación, 25 de junio de 1926, t. xxxvı, n. 46; Reglamento para recaudar impuestos y derechos de explotación de la pesca”, La prensa, Ciudad de México, 1 de enero de 1932, Centro de Estudios de Historia de México (en adelante CEHM-Carso), Oficialía Mayor, Sección 46, Carpeta 30.

33 Agricultura y Fomento (1919, p. 93).

34 "Fue abanderado un yate mexicano por el coronel E. Cantú", La Prensa, San Antonio, Texas, 1 de mayo de 1917; "Una palabra iba a costarle el empleo al comandante del barco Tecate”, La Prensa, San Antonio, Texas, 23 de febrero de 1919.

35 "Sale comisionado a investigar la pesca clandestina", La Prensa, San Antonio, Texas, 21 de noviembre de 1921; "Se evitará la pesca clandestina”, San Antonio, Texas, 27 de noviembre de 1921; "Una escuadrilla de aeroplanos vigilaran las costas del Pacífico", La Prensa, San Antonio, Texas, 23 de diciembre de 1921. 
la vigilancia marítima e instalaría una especie de fuerte en bahía Magdalena con cañones de artillería de grueso calibre. Los encargados estarían en contacto con torres inalámbricas que el gobierno había instalado en el litoral para informar sobre la presencia de posibles barcos "piratas". ${ }^{36}$

Entre 1922 y 1925 la vigilancia del Tecate fue reforzada temporalmente por los barcos de guerra Mayo y Yaqui que provenían de la costa de Sonora y navegaron desde el sur de la península hasta el puerto de Ensenada. ${ }^{37}$ Después fueron sustituidos por el $S A F$ número 1, barco de 126 toneladas dotado de radio y por el Curtisco de 32 metros de largo con motor de 450 caballos de fuerza y equipado con armas..$^{38}$ Este barco fue puesto en circulación por la Comisión Internacional de Pesca, organización creada en 1925 por los gobiernos de México y Estados Unidos con la idea de proteger, conservar y desarrollar los recursos marinos del océano Pacífico, específicamente entre California y el Distrito Norte de la Baja California. ${ }^{39}$ Con la operación del Curtisco, el gobierno de México logró complementar la vigilancia costera desde el puerto de San Pedro, California, hasta Ensenada con el fin de evitar la pesca furtiva en la frontera de ambos países (Véase Mapa 1).40 $\mathrm{Al}$ tiempo que comenzó a operar el SAF número 1 la secretaría puso en circulación dos lanchas veloces para hacer viajes cortos a las islas Coronado donde había actividad pesquera. ${ }^{41}$

36 "Será artillada poderosamente Bahía Magdalena”, El Heraldo de México, Los Ángeles, California, 8 de agosto de 1922.

37 "Un barco cuidará que no haya pesca clandestina", El Heraldo de México, Los Ángeles, California, 10 de enero de 1922; "Buques y aviones capturados por fuerzas mexicanas" El Hispanoamericano, San Francisco California, 21 de abril de 1923.

${ }^{38}$ Rodríguez, (1927 [2011], p. 183); La Prensa "A fines de año serán botados dos barcos guardacostas”, La Prensa, San Antonio, Texas, 23 de julio de 1926.

39 ADIIH-UABC, Microfilm r. 878.

40 "A fines de año serán botados dos barcos guardacostas", La Prensa, San Antonio, Texas, 23 de julio de 1926.

${ }^{41}$ Memorándum acerca de las condiciones en que se encuentra la pesca en las aguas de la Baja California, 1925, AGN, fondo Obregón-Calles, 8.35. 


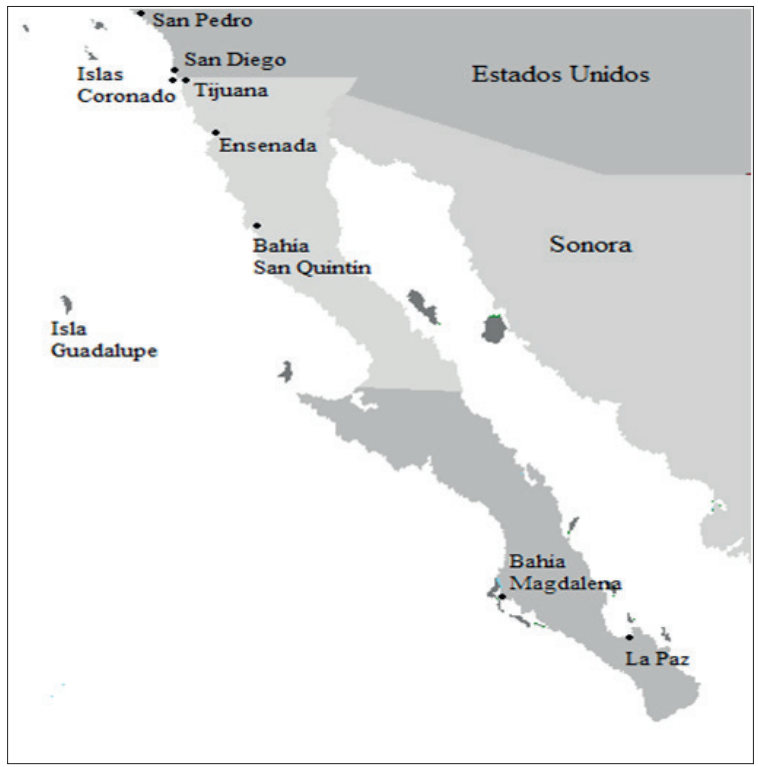

Mapa 1. Puertos y sitios con actividad pesquera

Fuente: Elaboración propia.

Al parecer la vigilancia en las costas de Baja California y sur de California repercutió favorablemente en la recaudación por concepto de expedición de permisos y pagos de derechos de explotación y exportación de productos marinos..$^{42}$ De acuerdo con un informe oficial, los ingresos de 1923 aumentaron 15 o 20 veces más sobre los obtenidos en el periodo 1915-1922. Hacia 1925 el gobierno mexicano esperaba tener una mejor vigilancia sobre las costas nacionales y el subsecretario de Agricultura y Fomento estimaba que al terminar ese año los ingresos por derechos de pesca en toda la república no serían menores a los cinco millones de pesos. ${ }^{43}$

La vigilancia e inspección de los pescadores, en especial de los permisionarios, constituyeron un aspecto importante para el gobierno mexicano que deseaba evitar la pesca no reglamentada y furtiva realizada en gran escala por extranjeros. Sin embargo, en la práctica no resultó fácil cumplir cotidianamente

42 Sierra y Sierra (1978, p. 59).

43 Memorándum acerca de las condiciones en que se encuentra la pesca en las aguas de la Baja California, 1925, ADIIH-UABC, AGN, fondo Obregón-Calles, 8.35. 
esas tareas porque eran variadas y complejas. Los empleados de las Oficinas de Servicios de Pesca en San Diego y San Pedro debían registrar la salida de los barcos y verificar en los muelles que los permisionarios llevaran al momento de partir la documentación en regla (permisos y despachos consulares) así como el equipo permitido para pescar en Baja California. En altamar, los encargados de la vigilancia en los guardacostas debían asegurar que sólo los pescadores autorizados hicieran capturas en las zonas asignadas, que explotaran las especies consignadas en el contrato, respetaran las vedas y no utilizaran métodos de pesca destructivos, por ejemplo el uso de la dinamita. Al regresar a los puertos de California los empleados encargados de cobrar debían reconocer las especies capturadas y determinar las cantidades, lo que implicaba otras formas de inspecciones y, sobre todo, debían calcular el peso del cargamento para hacer el registro y el cobro de derechos de explotación y exportación. Todas estas tareas no fueron fáciles por las razones que exponemos en el siguiente apartado.

\section{El estado en acción: vigilancia, inspección y recaudación}

En los primeros años del decenio 1920, el gobierno federal chocó con la resistencia de los pescadores californianos al reglamentar y gravar las pesquerías en el Distrito Norte. Algunos se resistieron a tal grado que incluso utilizaron las amenazas y la violencia armada. En diciembre de 1921, por ejemplo, los capitanes de los barcos pesqueros Yukón y Mabel se negaron a pagar permisos de pesca a los agentes del consulado y de la Secretaría de Agricultura y zarparon de San Pedro, California, rumbo al Pacífico mexicano a pescar con la amenaza de que utilizarían armas de fuego contra cualquier embarcación mexicana que intentara impedir sus actividades. Poco después hubo en efecto un tiroteo en las inmediaciones de Ensenada cuando el Tecate los encontró con capturas de pescado e intentó realizar una inspección. El conflicto se resolvió a favor de las autoridades mexicanas gracias a la intervención de un grupo de soldados que desde otro buque disparó contra el Mabel. ${ }^{44}$ Un año más tarde el guardacostas

44 Enrique Ferreira a Álvaro Obregón, 7 de diciembre de 1921, ADIIH-UABC, AGN, fondo Obregón-Calles, 4.9; “Un bote pescador americano fue capturado en aguas mexicanas", La Prensa, San Antonio Texas, 8 de diciembre de 1921; “La barca capturada en Baja California ya 
Mayo y otra embarcación pesquera estadunidense protagonizaron una refriega similar y motivada por las mismas razones. 45

A pesar de estas detenciones divulgadas por la prensa en Estados Unidos, un número indeterminado de barcos pesqueros provenientes de los puertos californianos continuó internándose sin permiso para pescar en aguas del litoral bajacaliforniano. Durante los años 1923 y 1924 el Mayo y el Yaqui realizaron varias capturas entre el puerto de La Paz y Bahía Magdalena. En 1923 dos embarcaciones navegaron sin permiso hasta el sur de la península en busca de concha perla, razón por la cual el Yaqui fue en su persecución, aunque no logró detenerlos; más tarde el Mayo capturó al Niagara que regresaba de extraer en esa zona un valioso cargamento de perlas. ${ }^{46}$

En 1924 los pescadores de California frecuentaron las islas Coronado, ubicadas a trece kilómetros de la costa de Tijuana y cercanas al puerto de San Diego, California, así como la Isla Guadalupe, ubicada al suroeste de San Quintín, a 240 kilómetros de la costa. Estas islas atrajeron la atención de los extranjeros debido a la existencia de recursos marinos y de otra naturaleza que podían explotar tierra adentro y en los litorales isleños. A pesar de la poca capacidad que tenía el guardacostas Tecate para vigilar la zona marítima cuya longitud era de unos 600 kilómetros, en 1925 siguió deteniendo algunas embarcaciones que pescaban de manera ilegal. ${ }^{47}$ En 1926, autoridades de las oficinas del Servicio de Pesca informaron a la prensa que un barco estadunidense llamado Mercedes había sido detenido en dichas aguas por pescar sin autorización. ${ }^{48}$

A finales de la década de 1920 las naves pesqueras ancladas en los puertos de California continuaban internándose de manera ilegal en aguas mexicanas

fue liberada”, La Prensa, San Antonio, Texas, 9 de diciembre de 1921; "Barco americano capturado por obregonistas", El Heraldo de México, Los Ángeles, California, 8 de diciembre de 1921.

45 "Un barco hace fuego contra guardacostas mexicano", El Hispanoamericano, San Francisco, California, 23 de diciembre de 1922.

46 "Buques y aviones capturados por fuerzas mexicanas", El Hispanoamericano, San Francisco, California, 21 de abril de 1923; "Han aparecido barcos piratas en las costas occidentales de Baja California”, El Heraldo de México, Los Ángeles, California, 16 de enero de 1923.

47 "Buques filibusteros aprehendidos", El Cronista del Valle, Brownsville, Texas, 27 de agosto de 1925 .

48 "El primer caso de la aplicación del tratado de pesca", El Cronista del Valle, Brownsville, Texas, 1 de mayo de 1926. 
y seguían resistiéndose a las inspecciones de los guarda costas del gobierno mexicano y del buque del Servicio Internacional de Pesca. Todavía en 1927, el Curtisco sorprendió a un grupo de goletas estadunidenses que realizaban pesca ilegal y capturó a dos de ellas. En 1928 el SAF número 1 encontró a un barco que había salido de San Diego a pescar en aguas mexicanas sin el permiso correspondiente. Al principio la tripulación se negó a aceptar una inspección pero al ser encañonados por el guardacostas se rindieron y fueron conducidos al puerto de Ensenada. ${ }^{49}$

A pesar de las detenciones, las embarcaciones estadunidenses continuaron con la extracción ilegal de recursos marinos en las costas bajacalifornianas todavía a principios de la década de 1930. La Secretaría de Agricultura y Fomento emitió un comunicado en 1932 en el que señaló que los guardacostas del Servicio de Pesca habían confiscado cinco embarcaciones de California por defraudar al erario al realizar actividades de extracción dentro de las aguas territoriales, sin contar con permiso, y por haber eludido el pago de los impuestos correspondientes, aunque los pescadores sostuvieron que habían realizado las capturas fuera de las aguas mexicanas..$^{50}$

Muchos permisionarios incurrían en irregularidades y varios pescadores extranjeros se negaban a pagar derechos con el argumento de que sus cargas no provenían del territorio mexicano, como en el caso anterior. ${ }^{51}$ Sin una mejor vigilancia, los empleados de las oficinas de Servicios de Pesca y de los consulados difícilmente podían comprobar lo contrario, sobre todo si se trataba de especies como atún, arenque, macarela, bonito y albacora cuyos bancos también se encontraban en aguas internacionales..$^{52}$

49 "Un barco pirata capturado por mexicanos", El Heraldo de México, Los Ángeles, California, 26 de mayo de 1928.

50 "Barcos piratas confiscados por México", La Prensa, San Antonio, Texas, 24 de diciembre de 1932 .

${ }^{51}$ Memorándum acerca de las condiciones en que se encuentra la pesca en las aguas de la Baja California, 1925, ADIIH-UABC, AGN, fondo Obregón-Calles, 8.35; Informe de José F. Farrel, vicecónsul en San Diego (1921), San Diego, 10 de enero de 1922, AHGE, fondo Embajadas de México en Estados Unidos (en adelante EMEU), leg. 623, exp. 5.

${ }^{52}$ Memorándum acerca de las condiciones en que se encuentra la pesca en las aguas de la Baja California, 1925, ADIIH-UABC, AGN, fondo Obregón-Calles, 8.35. 
Cabalmente las autoridades mexicanas sólo podían reclamar derechos de explotación a los pescadores extranjeros si los sorprendían sin permiso en el preciso momento de la pesca dentro de las tres millas náuticas de jurisdicción nacional. Eso, según el subsecretario de Agricultura, era difícil de lograr aun en el caso de que la secretaría dispusiera de suficientes barcos guardacostas, pues los navíos extranjeros operaban en pares o en grupos y los vigilantes iban en una sola embarcación. En esas circunstancias sólo podían detener a uno de los infractores mientras los otros huían con facilidad. Como puede verse, debido a la falta de vigilancia, muchos pescadores podían violar la reglamentación de pesca o hacer capturas cuantiosas sin ser vistos o detenidos por nadie. ${ }^{53}$

En un informe redactado en marzo de 1925, el director Forestal de Caza y Pesca Francisco Calles señaló la necesidad de contar por lo menos con seis agentes para el servicio de vigilancia; era necesario también aumentar la partida para la reparación de los barcos de las Oficinas del Servicio de Pesca, pero todavía a finales de la década de 1920 sus recursos eran limitados y persistían los problemas derivados de la falta de vigilantes. ${ }^{54}$

En abril de 1928, el gobernador del Distrito Norte, Abelardo L. Rodríguez, solicitó a la Secretaría de Agricultura y Fomento contratar más empleados e incrementar el presupuesto designado para sueldos de los empleados de las Oficinas del Servicio de Pesca. El subsecretario contestó que no era posible el incremento pero ofreció "prestar" personal de la Dirección Forestal de Caza y Pesca para apoyar a las oficinas durante la temporada de mayor movimiento. 55 Poco después, José María Tapia, jefe de las Oficinas de Servicios de Pesca, advirtió que la recaudación no mejoraría mientras persistiera la falta de barcos guardacostas. ${ }^{56}$

53 Memorándum acerca de las condiciones en que se encuentra la pesca en las aguas de la Baja California, 1925, ADIIH-UABC, AGN, fondo Obregón-Calles, 8.35.

54 "Se trata de concertar un pacto de caza y pesca entre México y Estados Unidos", El Heraldo de México, Los Ángeles, California, 29 de marzo de 1925; Dr. José Parres a José María Tapia, Fideicomiso Archivo Plutarco Elías Calles-Fernando Torreblanca (en adelante FAPEC-FT), Archivo Plutarco Elías Calles (en adelante APEC), expediente 14, inventario 5546, leg. 2/5.

55 Abelardo L. Rodríguez al Subsecretario de Agricultura y Fomento, 27 de abril de 1928, ADIIH-UABC, AGN, fondo Obregón-Calles, 5.23.

56 "Intensa labor desarrollada por el Jefe de los Servicios de Pesca del Gobierno mexicano, José María Tapia”, El Heraldo de México, Los Ángeles, California, 5 de mayo de 1928.

ESTUDIOS DE HISTORIA MODERNA Y CONTEMPORÁNEA DE MÉXICO 55, enero-junio 2018, 243-277

DOI: http://dx.doi.org/10.22201/iih.24485004e.2018.55.63299 
En el plano de la recaudación la Secretaría de Agricultura y Fomento tampoco tenía suficiente personal ni equipo para calcular y gravar adecuadamente los productos de pesca de sus permisionarios. Desde la creación de las Oficinas de Servicios de Pesca en 1917 en San Diego y San Pedro, California, la secretaría tenía asignados a tres celadores y a una secretaria para revisar y pesar los productos de los barcos que provenían de aguas mexicanas. Además, en ocasiones las autoridades locales y pescadores no estaban dispuestos a dejar que los empleados del Servicio de Pesca realizaran sus funciones, por lo que, en gran medida, las inspecciones y cobros de estos celadores fueron limitados y dependían de la buena disposición y voluntad de los pescadores y autoridades locales de los puertos para poder realizar sus funciones. ${ }^{57}$

Los problemas de falta de personal se reflejaron en los registros y recaudación obtenida. En 1920 el volumen total de especies capturadas por los pescadores californianos que descargaron en San Pedro y en San Diego, fue de 2049 toneladas, según los datos de los consulados, ${ }^{58}$ pero la Comisión de Pesca de Estados Unidos, que también llevaba registros con fines fiscales, consignó 3166.5 toneladas. La diferencia en los datos se acentuó en el periodo 1925-1927 si se comparan los registros del Servicio de Pesca y los de la Comisión de Pesca de California. La dependencia mexicana registró 5848.8 toneladas de pescado en 1925; 3582.9 en 1926 y 4824.3 en 1927, mientras que la Comisión de Pesca de California registró para esos mismos años 9673.8 , 10 096.5 y 24058.9 toneladas, respectivamente. ${ }^{59}$

La diferencia de cifras puede tener tres explicaciones: una, que los pescadores introdujeron sus capturas a Estados Unidos sin permisos después de evadir la vigilancia marítima mexicana así como el registro de las Oficinas de Servicios de Pesca y el pago correspondiente; dos, que los empleados de esas

57 Memorándum, "Sencilla solución del problema de la pesca en la Baja California”, México, 28 de marzo de 1936, AHGEBC, caja 413, exp. 852/671.42/998.

${ }^{58}$ Derechos cobrados en la oficina consular de México en San Diego, California durante el año de 1920, AHGE, exp.21-8-16.

59 Véase volúmenes 12, 13 y 14 de la Fish and Game; "Intensa labor desarrollada por el Jefe de Servicio de Pesca", El Heraldo de México, Los Ángeles, California, 5 de mayo de 1928; "Algo sobre el servicio de pesca del gobierno mexicano", El Heraldo de México, Los Ángeles, California, 5 de octubre de 1928. 
oficinas no pudieron pesar de manera acertada las cargas. La tercera explicación involucra prácticas corruptas de los empleados y funcionarios de la Secretaría de Agricultura y Fomento: los pescadores hicieron arreglos extraoficiales con ellos para no pagar derechos o bien los pagaron pero sin apego al peso real de las capturas.

En 1927, por ejemplo, diversos informes señalaron que Francisco Navarro Fragoso, jefe de las Oficinas de Servicio de Pesca en San Diego, California, recibió de los pescadores un cohecho que le permitió embolsarse 500 ooo pesos en un periodo de tres meses. ${ }^{60}$ El sustituto de NavarroFragoso, José María Tapia, señalaba poco después que los funcionarios y subordinados que le precedieron habían contribuido a la deficiente recaudación con su falta de honradez. Afirmó que las empresas empacadoras y los pescadores en grande sobornaban a los empleados para que registraran y cobraran en promedio sólo un 40 por ciento del total de las capturas que ingresaban a California, esta situación continuó en 1930, según un informe del secretario de Comunicaciones y Transportes, Juan Andrew Almazán, que presentó al presidente Pascual Ortíz Rubio después de visitar la región. ${ }^{61}$

Las prácticas corruptas también se presentaron entre los encargados de la vigilancia marítima. En septiembre de 1923 el capitán y el pagador del buque de guerra Yaqui, por ejemplo, fueron acusados de recibir dinero de los pescadores cuyos barcos eran detenidos con pesca no reglamentada a cambio de su liberación. La prensa informó que el guardacostas Yaqui capturaba con frecuencia navíos piratas y por lo tanto se suponía que los acusados habían hecho un gran "negocio fraudulento". ${ }^{62}$

No todos los problemas de recaudación tenían que ver con las distintas formas de evasión o los intentos de evasión de los pescadores y la corrupción.

${ }^{60}$ Gómez (2012, p. 141-42); Oficio de Luis M. Salazar dirigido a Abelardo L. Rodríguez, San Diego, California, 16 de octubre de 1927, FAPEC-FT, APEC, exp. 189, inv. 5010.

61 “Intensa labor desarrollada por el Jefe de los Servicios de Pesca del Gobierno mexicano", El Heraldo de México, Los Ángeles, California, 5 de mayo de 1928; "Bancos de pesca que son una verdadera riqueza”, La Prensa, San Antonio, Texas, 6 de agosto de 1930.

62 "Graves delitos atribuidos al comandante del Yaqui. Se asegura que hacía comercio inmoral con los piratas del Pacífico”, El Heraldo de México, Los Ángeles, California, 29 de septiembre de 1923. 
Recolectar el cobro de los derechos de explotación y exportación en los puertos de San Pedro y San Diego, California, no era una tarea sencilla. Las dependencias no sólo tenían problemas de personal sino dificultades para pesar las cargas por la falta de maquinaria y equipo. La secretaría carecía absolutamente de recursos humanos y materiales para hacer una pronta verificación del peso de las capturas y esta carencia era problemática para todos los involucrados porque había que dar entrada, registrar y pesar muchas toneladas de productos perecederos de rápida descomposición.

Obviamente, la recaudación tenía varias fugas, por eso, aunque las oficinas y los consulados recabaron 1386 ooo pesos durante el primer semestre de 1924, el gobierno central creía que esa cantidad no correspondía al valor de las extracciones realizadas por los barcos extranjeros que estimaba era de unos 3000,000 de pesos. ${ }^{63}$

Durante la presidencia de Emilio Portes Gil el gobierno tomó decisiones administrativas para agilizar los cobros en los puertos californianos. En 1929, el jefe de las oficinas del Servicio de Pesca, José Lorenzo Sepúlveda, mencionó en una entrevista que gracias al apoyo del gobierno federal había logrado llegar a un acuerdo satisfactorio con las empacadoras extranjeras con relación al pago de derechos de explotación y exportación pesquera. Para evitar malentendidos y conflictos entre inspectores y pescadores, -y probablemente actos de corrupción- una compañía estadunidense, avalada por la American Fish Commission para emitir certificados de pesos netos, se iba a encargar de pesar los productos capturados, de modo que los inspectores mexicanos solo vigilarían el procedimiento. ${ }^{64}$

\section{Estado, gobierno y concesionarios}

Las tareas de vigilancia, supervisión e inspección que realizaban los empleados y funcionarios de la Secretaría de Agricultura y Fomento a través de sus dependencias incluían a los concesionarios que, a diferencia de los permisionarios,

63 Sierra y Sierra (1978, p. 59); Hernández (1988, p. 12).

64 "Un verdadero triunfo para nuestro país”, Excélsior, Ciudad de México, 9 de septiembre de 1929, Archivo CEHM-Carso, Oficialía Mayor, Sección 12, Carpeta 124. 
eran un grupo constituido principalmente por mexicanos. A pesar de que eran pocos, sus actividades también requerían atención para asegurar que acataran cada uno de los artículos y cláusulas del contrato-concesión firmado con el gobierno y que cumplieran cabalmente sus obligaciones.

En los artículos y cláusulas de las concesiones de pesca otorgadas en 1917, 1919 y 1920 podemos observar la intención del gobierno de Carranza de inducir a los concesionarios a realizar negocios productivos y evitar los especulativos y de rentas. Interesado en el poblamiento y desarrollo económico del Distrito Norte de la Baja California, el gobierno otorgó como principales incentivos el derecho a ocupar terrenos nacionales para montar plantas industriales y la exención de impuestos en la importación de maquinaria, herramientas, materiales y artículos necesarios para la producción. Además, les permitió utilizar embarcaciones extranjeras para llevar a cabo sus capturas. Las obligaciones contraídas por los concesionarios eran varias pero las más difíciles de cumplir tenían que ver con la inversión de capitales y la creación y funcionamiento de fábricas. En cada contrato se especificó que el concesionario debía instalar una empacadora en el plazo de quince meses, después de la firma, e invertir en ella al menos 5 ooo pesos. ${ }^{65}$

En abril de 1917 el gobierno de Carranza otorgó una concesión a Juan H. Mendoza para realizar actividades pesqueras en Baja California con la obligación de establecer dos fábricas empacadoras. Por esas fechas, los militares Manuel Pérez Treviño y Juan C. Zertuche obtuvieron en sociedad autorización para capturar toda clase de pescado y mariscos en los litorales de la Isla Guadalupe así como para explotar por diez años la madera, sales, guano y ganado cabrío disponibles en la isla, pero con el compromiso de colonizarla. ${ }^{66}$

65 Véanse las concesiones otorgadas en 1919 y 1920 por cinco años a Samuel G. Vázquez, Francisco P. Estrada, Carlos G. Calles, José L. Navarro, Alfonso Schnable, Luis M. Salazar, Carlos R. Ptacknic y Victor Carusso, Periódico Oficial del gobierno del Distrito Norte de la Baja California, t. XXXII, núm 18, 15 de junio de 1919; t. XXXIII, n. 9, 13 de febrero de 1920; t. XXXIII, n. 11, 25 de febrero de 1920; t. XXXIII, n. 13, 5 de marzo de 1920; t. XXXIII, n. 16, 15 de marzo de 1920; t. XXXIII, n. 17, 25 de marzo de 1920; t. XxxIII, n. 52, 20 de septiembre de 1920; t. xxxIII, n. 65, 25 de noviembre de 1920; t. XxxIII, n. 71, 25 de diciembre de 1920.

66 Agricultura y Fomento (1917, p. 96-100). 
Mendoza obtuvo dos prórrogas para comprobar la instalación de las fábricas y por incumplimiento de este requisito el gobierno canceló su concesión el 6 de enero de $1920 .{ }^{67}$ La de Pérez Treviño y Zertuche fue cancelada en marzo de 1922, por no crear la colonia en la isla ni hacer los trabajos preparatorios de colonización. No obstante, antes de la cancelación los socios explotaron cientos de cabras y al menos durante marzo de 1920 una embarcación estadunidense llamada Silver Spray pescó en aguas de Baja California casi ocho toneladas de pescado fresco, amparada con un permiso de pesca de Pérez Treviño. ${ }^{68}$

Naturalmente, el auge pesquero y de la industria de alimentos enlatados en California permitía a los concesionarios especular con sus respectivas concesiones, pues tenían permitido traspasarlas a particulares y compañías -incluso a extranjeros si se apegaban a las leyes mexicanas-, podían obtener rentas o bien aportarlas a sociedades anónimas para convertirse en socios de éstas. En 1919 y 1920 el gobierno otorgó concesiones por cinco años a Samuel G. Vázquez, Francisco P. Estrada, José L. Navarro, Carlos R. Ptacknic, Carlos G. Calles, Alfonso Schnable, Víctor Carusso y Luis M. Salazar. ${ }^{69}$ Carecemos de información para saber cómo usaron Vázquez, Estrada, Navarro, Ptacknic y Calles sus respectivas concesiones. Schnable y Carusso las intercambiaron por acciones de sociedades anónimas que fueron organizadas por Carlos E. Bernstein y Abelardo L. Rodríguez, por separado. ${ }^{70}$ Luis M. Salazar utilizó su concesión para obtener rentas. Vale la pena documentar su caso, porque nos permite conocer los controles que ejerció la Secretaría de Agricultura y Fomento sobre los rentistas.

67 Periódico oficial del gobierno del Distrito Norte de la Baja California, t. xxxıII, n. 10, 20 de febrero de 1920.

68 Derechos cobrados en la oficina consular de México en San Diego, California durante el año de 1920, AHGE, exp. 21-8-16; Diario Oficial de la Federación, t. xx, n. 88, 18 de abril de 1922.

69 Véanse las concesiones otorgadas en 1919 y 1920 por cinco años a Samuel G. Vázquez, Francisco P. Estrada, Carlos G. Calles, José L. Navarro, Alfonso Schnable, Luis M. Salazar, Carlos R. Ptacknic y Victor Carusso, Periódico Oficial del gobierno del Distrito Norte de la Baja California, t. XXXII, núm 18, 15 de junio de 1919; t. XXXIII, n. 9, 13 de febrero de 1920; t. XXXIII, n. 11, 25 de febrero de 1920; t. xxxIII, n. 13, 5 de marzo de 1920; t. xxxIII, n. 16, 15 de marzo de 1920; t. XXXIII, n. 17, 25 de marzo de 1920; t. XXXIII, n. 52, 20 de septiembre de 1920; t. XXXIII, n. 65, 25 de noviembre de 1920; t. XxxIII, n. 71, 25 de diciembre de 1920.

70 Gómez (2007, p. 132). 
Salazar provenía de una familia de notables favorecidos en Sonora por el régimen del presidente Porfirio Díaz. Desde joven se desenvolvió en los negocios bajo la tutela de su tío Aurelio Sandoval, presidente de la compañía La Pescadora, que como vimos antes, hasta principios de 1917 fue la única concesionaria y usufructuaria de las riquezas costeras desde Baja California hasta Nayarit. A pesar de ser ajeno a la revolución y a la política, Salazar mantenía relaciones con miembros del grupo sonorense que gobernó en el periodo 1920-1934 y en el verano de 1920 colaboró con ellos en las negociaciones para retirar a Esteban Cantú del gobierno del Distrito Norte. Salazar asumió el puesto de gobernador de este Distrito en agosto de ese año, por encargo del presidente Adolfo de la Huerta, y aunque estuvo un mes en el puesto resultó favorecido con una concesión de pesca que le fue otorgada en julio. ${ }^{71}$

Gracias a esa concesión Salazar podía hacer cualquier tipo de captura de fauna marina en Baja California, Sonora y Sinaloa, con excepción de ballena y concha perlera, pero debía instalar en el plazo de dos años y medio al menos una fábrica para empacar, desecar o elaborar cualquier clase de alimento de origen marino. Según su contrato, vigente por diez años, estaba obligado a invertir en esas instalaciones al menos 5 ooo pesos. El documento especificaba que podría utilizar embarcaciones de matrícula extranjera para sus pesquerías e importar libres de impuestos la maquinaria y los enseres necesarios para la fábrica, sólo tenía que pagar por adelantado una cuota mensual determinada por explotación. $7^{2}$

Durante 1920, Salazar hizo negocios pesqueros por medio de Mauricio M. Salazar y Compañía, asociado con uno de sus hermanos, y dio cobertura a trece barcos de matrícula estadunidense para pescar en Baja California. Estas embarcaciones hicieron en conjunto 68 viajes en los cuales capturaron un poco más de 102 toneladas de pescado y más de 56 toneladas de langosta. ${ }^{73} \mathrm{~A}$ falta de información disponible suponemos que Salazar utilizó su concesión de la

${ }_{71}^{71}$ Diario Oficial de la Federación, t. xxiv, n. 63, 14 de julio de 1923; Calvillo (1994, p. 49-52).

72 Periódico Oficial del gobierno del Distrito Norte de la Baja California, t. XxXIII, n. 52, 20 de septiembre de 1920.

73 Derechos cobrados en la oficina consular de México en San Diego, California durante el año de 1920, AHGE, exp. 21-8-16. 
misma manera en 1921 y 1922, sin atender el requisito de la inversión y la creación de la fábrica. En junio de 1923 el subsecretario de Agricultura y Fomento le comunicó por escrito que su concesión, a punto de caducar, estaba siendo revisada porque ni siquiera había presentado proyectos de edificación de la empacadora; el 6 de septiembre de ese año fue cancelada por incumplimiento. ${ }^{74}$

Salazar regresó al negocio pesquero en noviembre de 1924 con una concesión que compró a un señor de nombre Eduardo González. De la documentación que hemos revisado se desprende que también utilizó ésta para obtener rentas, ahora por medio de una sociedad en comandita que formó con otro de sus hermanos. Pero en esta segunda vuelta los funcionarios y empleados de la Secretaría de Agricultura y Fomento lo vigilaron de cerca e intentaron sancionar sus infracciones.

En la vigilancia sobre Salazar estuvieron involucrados los jefes de las Oficinas de Servicios de Pesca en San Diego y San Pedro, California, los celadores de estas dependencias, el encargado de la oficina de Pesca en Ensenada, el administrador de la Aduana Marítima de Ensenada, un visitador, y de modo particular el agente de la Secretaría de Agricultura y Fomento con oficina en Tijuana, J. L. Fabela, quien probablemente comenzó a operar en 1923 y ya estaba instalado en 1924. La comunicación constante de estos funcionarios y empleados puso al descubierto las actividades rentistas de Salazar y una serie de infracciones cometidas en la primavera y el verano de 1925. En abril de 1925 Salazar violó el periodo de veda para la captura de langosta. La veda comenzó el 31 de marzo y la secretaría solicitó a los pescadores que pescaban y exportaban langosta a Estados Unidos presentarse con sus cargas en las Oficinas de Servicios de Pesca a más tardar los días 6 y 7 de abril para hacer trámites y pagos. Tres embarcaciones llamadas Yolanda, Invencible y Liberty, que supuestamente pescaban para Salazar, llegaron a San Diego cargados de langosta, el día 13; Salazar fue multado por no respetar el periodo de veda, aunque él argumentó que las capturas se habían realizado el 30 de marzo pero por distintos motivos, entre otros por fallas mecánicas, los barcos no pudieron llegar a las oficinas en

74 Diario Oficial de la Federación, t. xxIv, n. 63, 14 de julio de 1923 y t. xxv, n. 23, 27 de septiembre de 1923. 
las fechas señaladas. ${ }^{75}$ Por otra parte, según el artículo 17 de la ley de Pesca, los concesionarios debían llevar un libro de registro de sus negocios pesqueros. En mayo de 1925 la dirección Forestal de Caza a través de la oficina de Servicios de Pesca en San Diego solicitó a Salazar sus libros para revisión y como no los tenía, el jefe de la oficina le impuso una multa de 300 pesos. Salazar presentó después un libro que no fue aceptado porque no estaba autorizado ni refrendado por ningún funcionario.

En marzo de 1925 Salazar hizo gestiones para que el agente de la secretaría autorizara la salida de 600 barcos estadunidenses a pescar sardina y anchoveta en aguas mexicanas. El agente y el director Forestal de Caza y Pesca le negaron el permiso porque Salazar pretendía evadir el pago de cuotas de todo tipo y derechos de exportación. Entre enero y junio Salazar expidió miles de tarjetas identificación de pescadores en los puertos de San Diego y San Pedro las cuales, según él, hacían las veces de permisos para pescar sardina. El artículo trece de la ley de Pesca especificaba que los pescadores empleados por cada concesionario debían portar durante la pesca tarjetas de identificación registradas y visadas por las dependencias de la Secretaría de Agricultura y Fomento, pero Salazar las vendió como permisos de pesca y las expidió al margen de la secretaría. $^{76}$

En mayo de 1925 el subsecretario J. G. Parres solicitó al director Forestal de Caza y Pesca que todos los empleados del ramo de pesca desarrollaran una mayor vigilancia para evitar que embarcaciones pesqueras que salían de California hicieran capturas sin pagar los impuestos correspondientes. ${ }^{77}$ De mayo a agosto de ese año los funcionarios de la secretaría detectaron en las zonas de los litorales con mayor actividad pesquera a pescadores con tarjetas de identificación expedidas por Salazar. Aunque el administrador de la aduana marítima de Ensenada carecía de celadores y de embarcaciones para ejercer algún tipo

75 Copia de oficio de Luis M. Salazar Sociedad en Comandita dirigido a agente general de la Secretaría de Agricultura y Fomento, San Diego, California, 23 de abril de 1925, AHGEBC, caja 413, exp. 852/671.42/998.

${ }^{76}$ El jefe del departamento jurídico de la dirección Forestal de Caza y Pesca al director, México, D.F., 6 de octubre de 1925, AHGEBC, caja 413, exp. 852/671.42/998.

77 Memorándum del subsecretario de Agricultura y Fomento dirigido al director Forestal de Caza y Pesca, sl, 16 de mayo de 1925, AHGEBC, caja 413, exp. 852/671.42/998.

ESTUDIOS DE HISTORIA MODERNA Y CONTEMPORÁNEA DE MÉXICO 55, enero-junio 2018, 243-277

DoI: http://dx.doi.org/10.22201/iih.24485004e.2018.55.63299 
de vigilancia costera, inspeccionó a barcos anclados en El Sauzal (atracadero dependiente del puerto de Ensenada, localizado a cinco kilómetros al norte de éste) y reportó que no llevaban documentos oficiales sino una licencia de pesca expedida por Salazar. ${ }^{78}$ Más tarde, el capitán y un celador de la Oficina de Servicios de Pesca en San Diego llevaron a cabo inspecciones a barcos anclados en las costas de las islas Coronado y los días del 17 al 21 de julio corroboraron que más de 300 llevaban como único documento una tarjeta de identificación firmada por Salazar, quien a cambio de 30 dólares los autorizó a pescar carnada por un mes. ${ }^{79}$

Mediante más inspecciones y averiguaciones el agente de la secretaría, J. L. Fabela, corroboró que cientos de pescadores californianos salían a pescar sin autorización oficial. Los funcionarios de la secretaría se percataron que Salazar usurpaba sus funciones y engañaba a los pescadores haciéndoles creer que no requerían ningún trámite ni documentos oficiales para pescar en aguas del Distrito Norte. ${ }^{80}$ Claramente, Salazar menguaba los ingresos que las dependencias obtenían por permisos de pesca, cuotas de inspección y vigilancia y derechos de exportación.

Fabela solicitó al capitán del guardacostas Tecate impedir las operaciones de barcos de pesca que no portaran permisos oficiales y detener y conducir a Ensenada a los que intentaran hacerlo. ${ }^{81}$ A mediados de julio de 1925 informó al director Forestal de Caza y Pesca que había impuesto multas a Salazar por cada infracción que había descubierto e incluso había solicitado la intervención del agente del ministerio público federal, pero estaba consciente de que la

${ }^{78}$ Dirección General de Aduanas al Secretario de Agricultura y Fomento, México, 22 de agosto de 1925, AHGEBC, caja 413, exp. 852/671.42/998.

79 Informe del celador tesorero de la oficina de Pesca, San Diego, 11 de julio de 1925, AHGEBC, caja 413, exp. 852/671.42/998.

${ }^{80}$ Oficio de J. L. Fabela dirigido al director Forestal de Caza y Pesca, 15 de septiembre de 1925, AHGEBC, caja 413, exp. 852/671.42/998.

${ }^{81}$ Transcripción del jefe de departamento de administración y contabilidad para el director Forestal de Caza y Pesca, Ciudad de México, 28 de noviembre de 1925, AHGEBC, caja 413, exp. 852/671.42/998. 
vigilancia marítima no sería del todo eficaz para evitar que Salazar cometiera más infracciones. ${ }^{82}$

En opinión de Fabela, Salazar no pescaba, no compraba o vendía ni empacaba pescado, su negocio era vender permisos que le retribuían fabulosas ganancias, gracias a la simulación de que barcos pesqueros extranjeros -particulares y de empresas- pescaban como si fueran suyos. ${ }^{83}$ Fabela se empeñó en impedir los fraudes de Salazar a los pescadores y al gobierno mexicano así como evitar que los demás concesionarios siguieran esas prácticas, si bien hasta entonces Salazar era el único rentista que además se creía exento de tramitar permisos para sus supuestos barcos y de pagar cuotas de inspección, vigilancia, explotación y exportación. ${ }^{84}$

Durante 1925 la secretaría multó a Salazar cinco veces, además reclamó el pago de 50 ooo pesos por explotación pesquera y en agosto le suspendió su concesión. Finalmente, el 10 de diciembre la secretaría se la canceló. En el Diario Oficial publicado el 23 de enero de 1926 el gobierno explicó que Salazar había hecho caso omiso de los artículos y fracciones que se referían a las zonas de pesca reservadas, a periodos de veda y a pago de cuotas. Asimismo, no había presentado informes sobre las embarcaciones utilizadas en los trabajos de pesca y sobre el estado de su negocio. ${ }^{85}$

Como pudimos observar, las medidas implementadas por la autoridad federal durante los años de 1916-1932 tuvieron algunos saldos positivos. Por una parte, las funciones de recaudación, vigilancia e inspección en la región costera de Baja California por medio de la creación y reorganización de instituciones dependientes de la Secretaría de Agricultura y Fomento como fueron la Dirección de Pesquerías, Dirección General de Caza y Pesca, la Agencia de Pesca de Tijuana, así como las que estableció en San Diego y San Pedro, California como las Oficinas Fiscales de Pesca y las Oficinas del Servicio de Pesca. Por otra

\footnotetext{
82 J. L. Fabela al director Forestal de Caza y Pesca, Tijuana, 18 de julio de 1925, AHGEBC, caja 413, exp. 852/671.42/998.

83 Oficio de J.A Favela dirigido al juez primero del Distrito Norte de la Baja California, Tijuana, 21 de julio de 1925, AHGEBC, caja 413, exp. 852/671.42/998.

84 J. L. Fabela al director Forestal de Caza y Pesca, Tijuana, 28 de julio de 1925, AHGEBC, caja 413, exp. 852/671.42/998.

85 Diario Oficial de la Federación, t. xxxıv, n. 19, 23 de enero de 1926.
} 
parte, redactó una serie de leyes y reglamentos que fueron modificados a lo largo de los años para adecuarse a las condiciones reales en las que se realizaba la explotación de los recursos marinos y, por último, estableció un servicio de vigilancia marítima, antes inexistente, con el cual podía detener y perseguir a embarcaciones que pescaban de manera ilegal. Con esas medidas el gobierno federal modificó las condiciones de explotación de la pesca en la región y benefició al erario mediante la aplicación de controles, a través de la emisión de contratos y concesiones, señalamiento de cláusulas, registros de la extracción realizada por las empresas o permisionarios y sus embarcaciones. También contó con elementos legales para sancionar las faltas o rescindir contratos a los pescadores que no cumplieran con lo estipulado.

Sin embargo, las condiciones materiales y los recursos con los que contaron dichas instituciones y su personal no fueron siempre las adecuadas y generalmente la dinámica de la explotación pesquera en la región sobrepasó la capacidad de esas dependencias para llevar a cabo sus funciones de regulación de manera eficiente. En primer lugar, fue necesario contar con un número mayor de embarcaciones para vigilar la costa, más personal para poder inspeccionar y registrar de manera adecuada los barcos y su carga, carencias que aprovecharon los marineros para eludir el pago de derechos correspondientes. Contar con un buen sistema de vigilancia marítima e inspección portuaria no aseguraba una buena recaudación, pues algunos vigilantes asignados a los guardacostas y parte del personal de inspección en los puertos fueron proclives a la corrupción.

En términos generales podemos señalar que las medidas implementadas por los gobiernos en turno durante los años de 1916-1932 no lograron que todos los pescadores locales y extranjeros cesaran en sus intentos de defraudar al erario, sin embargo, pudimos observar que hubo una serie de acciones de la autoridad federal para frenar dicha situación, a pesar de contar con escasos recursos. 
Fuentes

Archivos

Acervo Documental del Instituto de Investigaciones Históricas, Universidad Autónoma de Baja California (ADIIH-UABC)

Archivo Histórico del Gobierno del Estado de Baja California (AHGEBC)

Archivo Histórico Genaro Estrada (AHGE)

Centros de Estudios de Historia de México (сенм-Carso)

Colección Archivo General de la Nación (AGN)

Embajadas de México en Estados Unidos (EMEU)

Fideicomiso Archivos Plutarco Elías Calles y Fernando Torreblanca (FAPEC-FT)

Fondo Archivo Plutarco Elías Calles (APEC)

Microfilm

Secretaría de Relaciones Exteriores

Oficialía Mayor

Hemerografía

Boletín de la California Fish and Game Commission

Boletín de la Secretaría de Agricultura y Fomento

Diario Oficial de la Federación

El Cronista del Valle, Brownsville, Texas

El Heraldo de México, Los Ángeles, California

El Hispanoamericano, San Francisco, California

La Prensa, San Antonio, Texas

Periódico Oficial del Gobierno del Distrito Norte de la Baja California

Tucsonense, Tucson, Arizona

Bibliografía

Arámburo Díaz, M. (1942). La pesca en México. México: Secretaría de Economía.

Bentz, L. y R. Schwemmer. (2002). "The Rise and Fall of the Chinese Fisheries in California", en S. Lan Cassel (ed.). The chinese in America. A History 
Drom Gold Mountain to the New Millennium. Estados Unidos: Altamira Press.

Brown, M. y P. Phillips. (1986).Craft and Mechanization in Nineteenth Century American Canning. The Journal of Economic History 46 (3), p. 743-756.

Calvillo, M. (1994).Gobiernos civiles del Distrito Norte de la Baja California 1920-1923. México: Secretaría de Gobernación, Instituto Nacional de Estudios Históricos de las Revoluciones de México.

Chenillo, P. (2011). Mercurio contra Baco y Birján. Impuestos a la "Industria del Vicio" en Baja California Norte, 1920-1935 [Ensayo para obtener el título de especialista en Historia Económica]. México: Universidad Nacional Autónoma de México.

Davis, K. (1993). Sardine Oil on Troubled Waters: The Boom and Bust of California’s Sardine Industry, 1905-1955 [tesis de Doctorado en Geografía]. Berkeley: Universidad de California.

Estes, D. (1977). “Kondo Masaharu, the Best of All Fishermen”. The Journal of San Diego History 223 (3), p. 1-19.

Felando, A. (1979). "The Fishing Industry in San Diego, From 1800 to the Present. On Overview", en F. R. Carl. They Came From the Sea. A Maritime History of San Diego. San Diego: Cabrillo Festival Historical Society.

GLass Cleland, R. (1922). A history of California. The Smerican Period. Nueva York: The Mac Millan Company.

Gómez Estrada, J. (2007). Gobierno y casinos. El origen de la riqueza de Abelardo L. Rodríguez. México: Instituto Mora/Universidad Autónoma de Baja California.

Gómez Estada, J. (2011), "Pesca e industria en el Distrito Norte de la Baja California, 1909-1919”, en L. C. León (coord.). Frontera, territorio y sociedad. Estudios históricos sobre Baja California. Tijuana: Centro Cultural Tijuana, Consejo Nacional para la Cultura y las Artes.

Gómez Estrada, J. (2012). Lealtades divididas. Camarillas y poder en México, 1913-1932. México: Universidad Autónoma de Baja California/Instituto Mora. Baja California, p. 117-137. México: Consejo Nacional para la Cultura y las Artes. 
Henderson, D. (1964). Agriculture and Livestock Raising in the Evolution of the Economy and Culture of the State of Baja California, Mexico [tesis de Doctorado en Geografía]. Universidad de California.

Hernández Fujigaki, G. (1998). 75 años de historia de la pesca en México, 19121987. Avances y retos. México: Secretaría de Pesca.

Lindsey, M. (1936). Lower California as a Field of American Interest in the Nineteenth Century, [tesis de Maestría en Artes] Universidad de Southern California.

Loyo CAmacho, M. (2004). Joaquín Amaro y el proceso de institucionalización del ejército mexicano, 1917-1931. México: Universidad Nacional Autónoma de México/Fondo de Cultura Económica/Instituto Nacional de Estudios Históricos de las Revoluciones de México.

Gómez, M. (1918). Breves apuntes geográficos del Distrito Norte de la Baja California. sl. se

McEvor, A. (1983). "Law, Public Policy, and Industrialization in the California Fisheries, 1900-1925”. Business History Review, v. 57, n. 4, p. 494-521.

McEvoy, A. (1986). The Fisherman's Problem. Ecology and Law in the California Fisheries, 1850-1980. Estados Unidos: Cambridge University Press.

Newell, D. (1988). “The rationality of Mechanization in the Pacific Salmon-Canning Industry Before the Second World War”. Business History Review, v. 62, p. 626-655.

O’Bannon, P. (1982). “Technological Change in the Pacific Coast Canned Salmon Industry, 1900-1925: A Case Study”. Agricultural History 56 (1), p. 151-166.

O’Bannon, P. (1987). "Waves of Change: Mechanization in the Pacific Coast Canned-Salmon Industry, 1864-1914”. Technology and Culture 28 (3), p. 558-577.

Pincetl, S. (1999). Transforming California. A Political History of Land Use and Development. Estados Unidos: The John Hopkins University Press.

Plasencia de la PARRA, E. (2010). Historia y organización de las fuerzas armadas en México, 1917-1937. México: Universidad Nacional Autónoma de México/Siglo xxi. 
Roy, M. (1990). “A History of the Seafood Industry”, en M. Roy y G. J. Flick. The sea food industry. Estados Unidos: Spring Science/Business Media, LLC.

SAmAniego López, M. (1998). "La formación de la burguesía revolucionaria: el gobierno de Abelardo L. Rodríguez”, en Ensenada: nuevas aportaciones para su historia, p. 543-596. México: Universidad Autónoma de Baja California.

Schantz, E. (2011). "El botín fronterizo de los placeres arriesgados: Estado revolucionario e ingresos públicos en Baja California, 1910-1926”, en J. A. Gómez y A. Almaraz (coords.). Inversiones, colonización y desarrollo económico en el noroeste de México, 1870-1940, p. 179-216. México: Universidad Autónoma de Baja California/El Colegio de la Frontera Norte.

Secretaría de Fomento, Colonización e Industria. (1913). Mención de la comisión del Instituto Geológico de México que exploró la región norte de Baja California. México: Secretaría de Fomento.

Sierra, C. y Sierra Zepeda J. (1958). Reseña histórica de la pesca en México, 1821-1977. México: Editorial Helio-México.

Uhthoff López, L. (2009). "El departamento de contraloría y la búsqueda del control del presupuesto en México, 1917-1932. Una aproximación”. Secuencia 74, p. 83-101.

Uno, S. (1929). The Sardine Canning Industry in California [tesis de Maestría en Artes]. Universidad de Southern California. 